\title{
Resuscitative endovascular balloon occlusion of the aorta (REBOA): an updated review
}

\section{Oclusão ressuscitativa por meio de balão endovascular da aorta (REBOA): revisão atualizada}

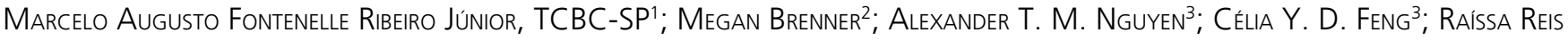
de-Moura ${ }^{1}$; Vinicius C. Rodrigues'; Renata L. Prado ${ }^{1}$

\section{A B S T R A C T}

In a current scenario where trauma injury and its consequences account for $9 \%$ of the worlds causes of death, the management of noncompressible torso hemorrhage can be problematic. With the improvement of medicine, the approach of these patients must be accurate and immediate so that the consequences may be minimal. Therefore, aiming the ideal method, studies have led to the development of Resuscitative Endovascular Balloon Occlusion of the Aorta (REBOA). This procedure has been used at select trauma centers as a resuscitative adjunct for trauma patients with non-compressible torso hemorrhage. Although the use of this technique is increasing, its effectiveness is still not clear. This article aims, through a detailed review, to inform an updated view about this procedure, its technique, variations, benefits, limitations and future.

Keywords: Radiology, Interventional. Multiple Trauma. Abdomen. Shock, Hemorrhagic.

\section{INTRODUCTION}

Every year more than five million people die around the

Eworld from traumatic injury and its consequences'. This accounts for $9 \%$ of worldwide mortality; greater than the combined deaths caused by HIV/AIDS, malaria and tuberculosis'. In 2015, 214,000 Americans died from traumatic causes ${ }^{2}$. Whilst hemorrhage is the second highest cause of trauma death $(30-40 \%$ of trauma deaths), it is also the most preventable cause ${ }^{3,4}$. Fatalities caused by traumatic hemorrhage most commonly occurred in the acute stages of injury; $36 \%$ of patients found or declared deceased at the scene of injury had exsanguinated and the majority of exsanguinations once admitted to hospital occurred in the first 48 hours of admission ${ }^{4}$. Traumatic hemorrhage can be subdivided into compressible and non-compressible, with the former type being easier to control and carrying less risk of mortality ${ }^{5,6}$. Non-compressible hemorrhage of the torso (NCTH) is defined using the criteria in table 1 and is considerably harder to control, with an overall mortality of up to $44.6 \%{ }^{5}$.

Table 1. Non-compressible torso hemorrhage, which consists of one of the anatomic criteria PLUS the physiological criterium. Adapted from Kisat et al. ${ }^{5}$.

Anatomic criteria Physiological criterium

1. Pulmonary injury (massive haemothorax, pulmonary vascular injury)

2. Solid organ injury = grade 4 (liver, kidney, spleen)

Systolic blood pressure

3. Named axial torso vessel $<90 \mathrm{mmHg}$

4. Pelvic fracture with ring disruption

1 - Santo Amaro University, Discipline of General Surgery and Trauma, São Paulo, SP, Brazil. 2 - University of Maryland, RA Cowley Shock Trauma Center, Baltimore, MD, USA. 3 - University of New South Wales, School of Medicine, Sydney, New South Wales, Australia. 
The current management of NCTH is highly invasive; laparotomy is used to cause hemostasis in intraabdominal hemorrhage, while patients who present or progress to refractory haemorrhagic shock are subjected to open thoracotomy with cross-clamping of the aorta to resuscitate the cardiovascular system ${ }^{7}$. Resuscitative Endovascular Balloon Occlusion of the Aorta (REBOA) is an improving technique involving expansion of an endovascular balloon to provide haemorrhagic control. It is less invasive than emergency department thoracotomy (EDT), but only one prospective study has been completed that compared the clinical use of open thoracotomy and REBOA ${ }^{8}$. The results from this study are optimistic. After the procedure, REBOA patients regained a higher mean systolic blood pressure compared to patients undergoing open thoracotomy $(90.0 \pm 52.9 \mathrm{mmHg}$ vs. $64.6 \pm 61.1 \mathrm{mmHg}, \mathrm{p}=0.029$ ). Importantly, there was no significant difference in overall mortality between the two techniques (REBOA, $71.7 \%$ vs. open, $83.8 \% ; p=0.120)^{8}$.

According to Qasim et al. ${ }^{7}$, the REBOA technique had its origins during the Korean War, and its progress to civilian use is linked to its use in the military. A retrospective study of the UK Joint Theatre Trauma Registry found that roughly $20 \%$ of combat casualties might have been treated with REBOA ${ }^{9}$. Recently, one of the first prospective cohort studies comparing REBOA with open methods of endovascular occlusion (i.e. EDT) has been completed with promising results on patient mortality, as explained above ${ }^{8}$.

As REBOA becomes increasingly used in major trauma centers in the United States and worldwide, extensive research and training will need to be conducted in this area to ensure that the method is reliable and well suited to its indications ${ }^{10}$. This review provides an update on the current literature and context surrounding REBOA. We also review the technique itself, its indications and uses, benefits and limitations, identifying areas for future research.

\section{TECHNIQUE}

REBOA involves rapidly placing a flexible catheter into the femoral artery, manoeuvring it into the aorta and inflating a balloon at its tip. This prevents blood flow distal to the balloon and significantly decreases any non-compressible intrathoracic/intra-abdominal bleeding. Due to the risk of ischemia-reperfusion injury, which will be discussed later in the review, it is a temporary maneuver in the emergency department to prepare the patient for a surgical procedure ${ }^{11,12}$.

As an alternative to conventional resuscitative thoracotomy, REBOA has been shown to preserve myocardial and cerebral tissue perfusion in a less invasive fashion ${ }^{13}$. Its aims are to maintain cerebral and coronary circulation and temporarily control arterial hemorrhage from the injured organ via occlusion using balloon inflation of the aortic lumen ${ }^{14}$.

The use of REBOA begins with patient selection. It is indicated for use in any patient presenting with hypotension $(\mathrm{SBP}<90 \mathrm{mmHg})$ after trauma who proves to be a partial responder or non-responder to fluids and/ or blood components, as per the Advanced Trauma Life Support guidelines. Widened mediastinum, evidence of hemorrhage above the potential balloon landing site or a penetrating thoracic injury are contraindications to its use. Currently in USA, traumatic brain injuries are no longer a contraindication to the method ${ }^{15}$.

Any physician adept at the Seldinger's technique ${ }^{16}$ can perform a REBOA catheter insertion at the patient's bedside. Common femoral artery access is obtained via the insertion of a femoral arterial introducer, varying in size from $7 \mathrm{Fr}$ to $14 \mathrm{Fr}$, depending on the particular device used ${ }^{16}$. The site at which femoral access is obtained is shown in figure 1.

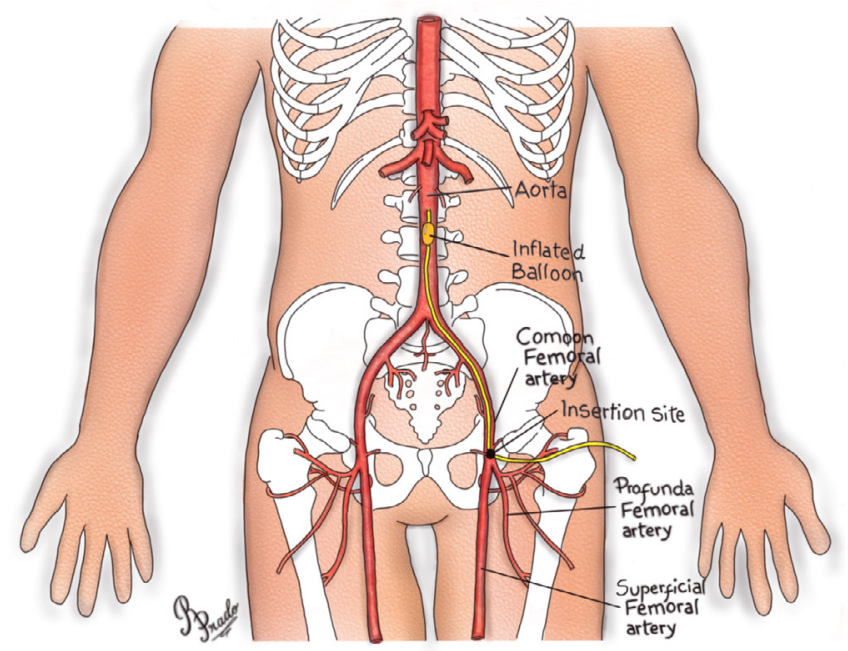

Figure 1. Femoral access to insertion of REBOA. 
Recent advances, particularly the development of balloon catheters deliverable via smaller 7Fr sheaths have led to new enthusiasm for this technique for trauma patients. However, although it has now become commercially available, the evidence of efficacy is limited ${ }^{17}$.

Common femoral artery cannulation can be accomplished via surgical cut-down, a blind percutaneous approach, or most recently, with the use of bedside ultrasound. Ultrasound guidance access should be considered the standard of care whenever feasible, since its use affords placement precision, effectively identifies aberrant femoral anatomy and mitigates the risk of arterial injury. It is also an alternative for achieving femoral access in patients with severe hypotension or with no palpable pulse to guide needle insertion ${ }^{18}$. Access has been found to be the rate-limiting step of REBOA and therefore is a critical skillset to perform the procedure.

The choice of REBOA device to be used dictates subsequent upsizing of the $5 \mathrm{Fr}$ sheath. A micropuncture with this size of sheath is done in order to reduce the risk of hematoma or vessel injury if initial placement is imprecise ${ }^{19}$. The use of a smaller introducer catheter results in a more gradual enlargement of the arteriotomy with sheath upsizing, particularly important in vessels with atherosclerotic disease.

There are several types of balloon for use in the REBOA, but the balloon more commonly selected is the ER REBOA, which is 7Fr compatible. It possesses an atraumatic flexible tip, has an arterial monitoring port proximal to the balloon that can be used to accurately measure pre-occlusion blood pressure as well as arterial response to REBOA, and external markings on the catheter that facilitate placement and were specifically designed for trauma applications ${ }^{18,20}$. Other alternative balloons include the Coda $^{\circledR}$, the Reliant ${ }^{\circledR}$ and the Berenstein ${ }^{\circledR 20}$.

After insertion of the femoral artery sheath, a REBOA catheter is placed into the aorta and aortic occlusion is performed. The placement of the balloon catheter in the aorta should be decided prior to insertion, and the levels of the aorta, chosen according to figure $2^{21}$. These levels are usually set according to the three zone classifications: Zone I (thoracic aorta, from the left subclavian artery to the celiac artery), Zone II (between celiac and renal arteries), and Zone III (infra-renal placement) ${ }^{22}$, and depend on the site(s) of hemorrhage.

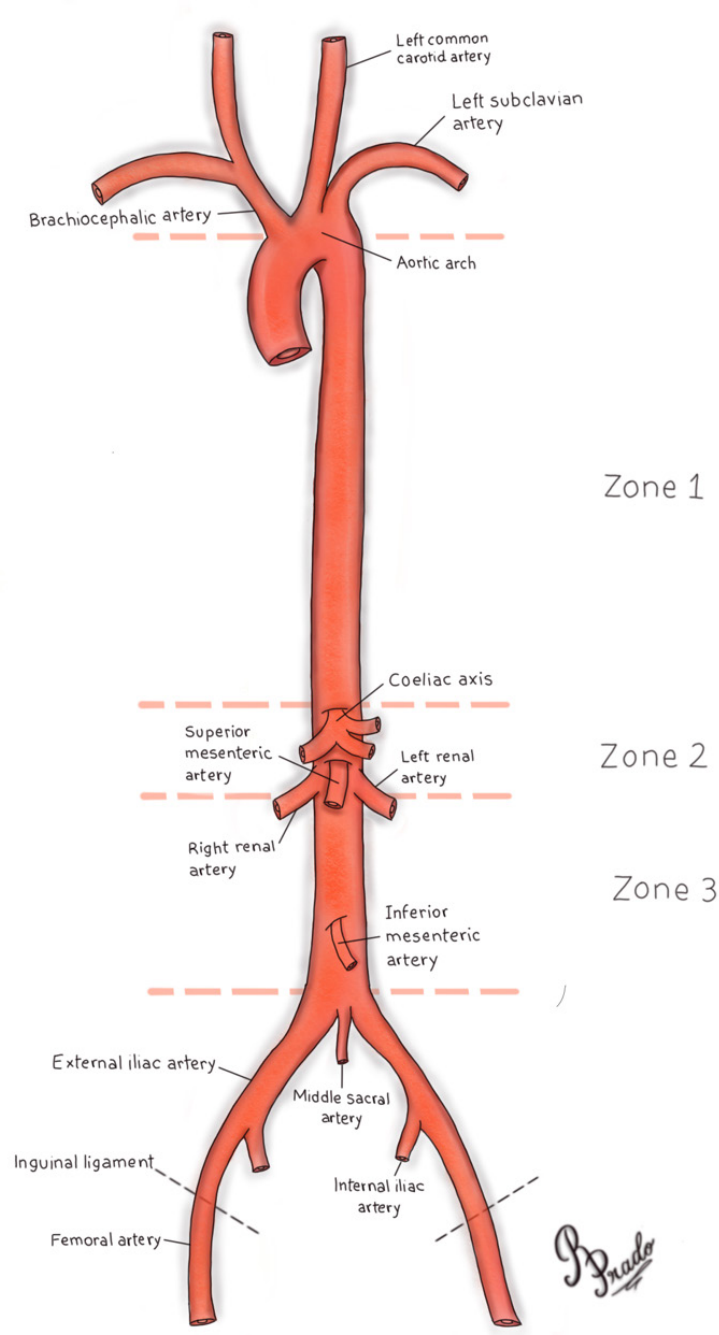

Figure 2. Illustration of the zone classification for REBOA location.

The aortic zone for occlusion is selected based on the primary assessment: Zone I is usually the choice for the placement in patients with suspected intra-abdominal hemorrhage, while Zone III is chosen in patients with hemorrhage from a confirmed pelvic fracture ${ }^{23}$. REBOA catheter positioning is confirmed by portable chest or abdominal radiography in the Emergency Room ${ }^{23}$.

To inflate the balloon, a solution of sterile saline and iodinated contrast can be used. The balloon should be inflated until the blood pressure is augmented and contralateral femoral pulse is stopped; currently, the volumes used are approximately $8 \mathrm{~mL}$ for Zone I and $3 \mathrm{~mL}$ for Zone $1 \|^{20}$. The physician should be careful not to over-inflate the balloon, as over-inflation will rupture the balloon or the blood vesse ${ }^{20}$. Balloon inflation 
should be guided by fluoroscopy, if available at the ER area, by the hemodynamic response and/or by the loss of the contralateral pulse. It is possible to verify the balloon position using $x$-ray or fluoroscopy (the $x$-ray is the preferred method, due to the availability in the resuscitation areas) ${ }^{24}$.

After balloon inflation, the patient should be taken to the operating room or angiography suite, where the necessary procedure will be done. Once specific vascular control or definitive hemorrhage control has been obtained, balloon deflation and sheath removal should be performed ${ }^{19}$.

At this stage, health care professionals should be prepared for instances of new bleeding. Metabolic consequences may also appear due to significant reperfusion effect and the surgical team must ensure all necessary support for a possible reintervention. Some vascular repair may be necessary after sheath removal ${ }^{22}$.

When REBOA is no longer required, the deflated balloon may be removed from the sheath. The sheath's removal depends on its size and how it was introduced. If the introducer sheath was placed by open arterial cutdown, then open surgical repair of the arterial access site is necessary. The femoral artery proximal and distal to the sheath entry site should be exposed to allow control. Proximally, this may require dissection of $2 \mathrm{~cm}$ to $3 \mathrm{~cm}$ underneath the inguinal ligament when the sheath removal is performed via standard cutdown ${ }^{18,20}$. However, if the sheath used has a smaller caliber (i.e. 7Fr) and was placed percutaneously, the sheath may be removed and direct pressure held at the arterial site, above the skin puncture site. Full occlusive direct pressure is applied for ten minutes, with gradual decrease in pressure every five minutes for a total of 30 minutes $^{20}$.

Lastly, restoration of flow through the arterial segment should be confirmed using manual palpation for pulses distally and continuous wave doppler of both the artery and more distal extremity. If there is any uncertainty of flow, it is recommended to perform an angiogram, and immediate intervention if any abnormalities are noted ${ }^{20}$.

\section{VARIATIONS OF REBOA USE}

Developed from the convergence of trauma and endovascular surgery, REBOA has increasingly been used at select trauma centers as a resuscitative adjunct for trauma patients with life-threatening $\mathrm{NCTH}^{25}$. The intervention can be performed with a full occlusion of the aorta, which is known as complete REBOA (CREBOA), with a partial occlusion (pREBOA) or with an intermittent occlusion (iREBOA) ${ }^{11,26}$.

Although the use of REBOA in clinical practice is increasing, animal data suggests that prolonged occlusion of the aorta is associated with ischemia-reperfusion injury and potentially an increased risk of death ${ }^{27}$. The profound distal ischemia means that there is a maximal duration of use for REBOA that cannot be extended ${ }^{11}$. Periods of occlusion exceeding 40 minutes can result in irreversible organ injury and death. Additionally, supraphysiologic increases in blood pressure proximal to the occlusion balloon during CREBOA can contribute to cardiac failure and exacerbation of traumatic brain injury ${ }^{26}$.

These limitations have led to the development of pREBOA, whereby the balloon is deflated slightly, allowing a degree of flow beyond the balloon 27 ; and iREBOA, in which the balloon is fully deflated for brief periods of reperfusion ${ }^{11}$. The refinement of the technique attempts to minimize distal ischemia and extend the duration of REBOA ${ }^{27}$.

Several clinical reports suggest that partial aortic flow restoration via partial aortic occlusion may serve to mitigate the adverse effects of aortic occlusion on both proximal and distal vascular beds, whilst aiming to limit ongoing hemorrhage in the bleeding patient. Generally, these researchers and clinicians have described this therapeutic strategy as pREBOA. However, the application known as pREBOA has been heterogeneous and the methodology to perform it remains ill-defined ${ }^{28}$.

An alternative approach to mitigate the consequences of sustained aortic occlusion is the concept of iREBOA. Intermittent REBOA represents the cyclical full inflation and full deflation of a balloon catheter in the management of physiologically deranged patients. This represents a binary approach to resuscitation, where aortic occlusion is repeatedly toggled from "on" to "off" to minimize the ischemic burden to downstream tissues. As with pREBOA, the application of iREBOA remains illdefined, with similar challenges regarding quantification, data capturing and reporting ${ }^{28}$.

Although these techniques are still under 
analysis, some studies demonstrate that pREBOA maintained normal physiology better than CREBOA, minimized the systemic impact of distal organ ischemia, and reduced hemodynamic instability, allowing longer periods of intervention ${ }^{26}$. Studies have also shown that IREBOA increased the tolerable duration of the aorta occlusion beyond 80 minutes without ischemic complications ${ }^{11}$.

Currently, whilst the consensus on which technique is superior remains unclear, in a study conducted in 2017 examining the preferences of surgeons before and after the 2017 Endovascular and Hybrid Trauma and Bleeding Management Symposium, the vast majority of participants favored partial REBOA over intermittent REBOA (81,6\% preferred partial REBOA $)^{29}$.

Innovation in the development and employment of endovascular resuscitative adjuncts continues at an impressive pace. The evolution of devices and concepts involved in these efforts will inevitably lead to a growing lexicon of endovascular intervention for resuscitation ${ }^{28}$.

\section{BENEFITS}

REBOA is recognized as a minimally invasive and lower risk procedure in comparison to EDT, particularly in minimizing potential exposure to bloodborne pathogens ${ }^{30}$. When compared to open procedures for aortic occlusion, such as EDT, REBOA was found to more consistently achieve hemodynamic stability $(47,8 \%$ vs. $27,9 \%, p=0.014)$, defined as SBP>90mmHg for more than five minutes ${ }^{8}$. Furthermore, there was no significant difference found in mortality rates between both procedures $^{8}$. Whilst originally adopted as a technique of aortic occlusion for controlling NCTH, after being shown as effective in pelvic hemorrhage, studies have demonstrated the usefulness of intra-aortic balloon occlusion in cases such as an emergency Caesarean hysterectomy in a pregnant Jehovah's Witness patient ${ }^{31}$, major upper gastrointestinal bleeding in patients with Crohn's disease ${ }^{32}$, restoring maternal blood in postpartum hemorrhage, and ruptured abdominal aortic aneurysm ${ }^{33}$.

Additionally, complications related to use of REBOA are uncommon. In a retrospective review conducted over five years of all patients in the US that underwent REBOA for NCTH ( $n=48)$, none of the patients experienced significant vascular complications that required amputations ${ }^{18}$. Time required for aortic occlusion was also significantly shorter than EDT $(p=0.003)$, with a retrospective review performed by Romagnoli et al. finding a median time of 245 seconds required for occlusion after arterial access was obtained ${ }^{34}$. In an animal study conducted on porcine models of hemorrhagic shock, REBOA resulted in lower serum lactate levels, less acidosis, lower $\mathrm{pCO}_{2}$ levels and required smaller volumes of fluid and norepinephrine when compared to thoracotomy and occlusion by clamp ${ }^{35}$.

\section{LIMITATIONS}

Whilst REBOA lowers risks of contamination for the patient, the minimally invasive nature of the procedure reduces exposure to the torso, a disadvantage when emergency procedures such as relieving pericardial tamponade, tension pneumothorax or performing an open chest cardiac massage are required ${ }^{36}$ Reported complications related to the use of REBOA has been minimal. However, there have been cases of lower limb ischemia and external iliac artery injury reported ${ }^{37}$. Lower limb ischemia for prolonged periods can result in irreversible damage due to limited reperfusion.

Furthermore, prolonged periods of hypertension caused by REBOA can lead to cardiovascular complications, due to the increased afterload on the left ventricle of the heart ${ }^{38}$. In a 7-year retrospective study conducted in Tokyo, Japan, of all patients $(n=24)$, there were three reports of complications, two cases of lower limb ischemia and one case of external iliac artery injury, all of which required lower limb amputation ${ }^{37}$. Complications may also arise during the balloon deflation, such as release of inflammatory mediators, complement, ROS, embolism, metabolic acidosis and hemorrhage to the affected area that had previously attained hemostasis ${ }^{35}$. However, variables such as approach to treatment of the patient, technique used and management strategies which vary across different health institutions globally, can largely affect the complications that REBOA has on its patients ${ }^{39}$. This must be addressed in future, in order to minimise such complications. 


\section{FUTURE}

REBOA has vast potential in the future as an adjunct to other trauma and resuscitative techniques and perhaps even in replacing EDT in some emergency scenarios. However, further studies must be conducted in order to establish the benefits of this procedure, as well as its optimal indications ${ }^{7}$. Large multicenter prospective studies on trauma patients should be performed, evaluating the efficacy and complications of REBOA ${ }^{39}$. Transdisciplinary training, such as through the established Endovascular Skills for Trauma and Resuscitative Surgery (ESTAR) and Basic Endovascular Skills for Trauma (BEST) courses $^{40}$, must be expanded in future and made more accessible to providers, to ensure knowledge of REBOA is adequate to allow subsequent practice of the technology.

Currently, new developments to the technology of REBOA are emerging. The use of smaller 7Fr introducer arterial sheaths for REBOA have been hypothesized to be a safer alternative to the currently used larger sheaths ${ }^{41}$. New techniques such as the use of the mid-sternum landmark instead off fluoroscopic image guidance for deployment of the balloon, have been investigated as a safe alternative to facilitate situations where fluoroscopic imaging is not available ${ }^{42}$. Furthermore, a new smaller profile, fluoroscopy-free ER-REBOA catheter, has been developed by Pryor Medical ${ }^{36}$.

Recently, there has been emerging data of the use of resuscitative balloon technology in occlusion of the inferior vena cava, known as REBOVC. In a novel animal study conducted by Reynolds et al. ${ }^{43}$, REBOVC prolonged time to death and significantly reduced blood loss in swine liver models, when compared to no control of the suprahepatic inferior vena cava. This has immense potential for use in emergency situations such as retrohepatic inferior vena cava injuries, where it is difficult to appropriately expose and isolate the vasculature ${ }^{43}$.

Finally, to minimize complications and lower mortality rates of the use of REBOA, a uniform management strategy or clinical guideline must be established and used to allow for optimal utilisation of this technology ${ }^{36}$.

\section{CONCLUSION}

REBOA is an emergent and innovative technique that is increasingly being recognized and performed by health care providers in trauma centers internationally. Its minimally invasive technique has continually been developed and modified over the past few years, utilizing new technology to decrease complications and maximize benefits. However, for continual expansion and use of REBOA in future, further research and training must be conducted to ensure adequate knowledge and warranted safety of the procedure as a resuscitative technique.

\section{R E S U M O}

Em um cenário atual onde a lesão traumática e suas consequências representam $9 \%$ das causas de morte no mundo, o manejo da hemorragia não compressível do tronco pode ser problemático. Com a melhoria da medicina, a abordagem desses pacientes deve ser precisa e imediata, para que as consequências possam ser mínimas. Portanto, visando o método ideal de manejo, estudos levaram ao desenvolvimento da técnica de oclusão ressuscitativa por balão endovascular da aorta (Resuscitative Endovascular Balloon Occlusion of the Aorta - REBOA). Este procedimento foi utilizado em centros de trauma selecionados como um complemento durante a reanimação para pacientes vítimas de trauma com hemorragia não compressível do tronco. Embora o uso dessa técnica esteja aumentando, sua eficácia ainda não é clara. Este artigo objetiva, por meio de uma revisão detalhada, trazer uma visão atualizada sobre este procedimento, sua técnica, variações, benefícios, limitações e futuro.

Descritores: Radiologia Intervencionista. Traumatismo Múltiplo. Abdome. Choque Hemorrágico. 


\section{REFERENCES}

1. World Health Organization. Injuries and violence: the facts 2014. Geneva: WHO; 2014.

2. Murphy SL, Xu J, Kochanek KD, Curtin SC, Arias E. Deaths: final data for 2015. Natl Vital Stat Rep. 2017;66(6):1-75.

3. Kauvar DS, Lefering R, Wade CE. Impact of hemorrhage on trauma outcome: an overview of epidemiology, clinical presentations, and therapeutic considerations. J Trauma. 2006;60(6 Suppl):S3-11.

4. Kauvar DS, Wade CE. The epidemiology and modern management of traumatic hemorrhage: US and international perspectives. J Crit Care. 2005;9 Suppl 5:S1-9.

5. Kisat M, Morrison JJ, Hashmi ZG, Efron DT, Rasmussen $\mathrm{TE}$, Haider $\mathrm{AH}$. Epidemiology and outcomes of non-compressible torso hemorrhage. J Surg Res. 2013;184(1):414-21.

6. Kragh JF Jr, Littrel ML, Jones JA, Walters TJ, Baer DG, Wade $C E$, et al. Battle casualty survival with emergency tourniquet use to stop limb bleeding. J Emerg Med. 2011;41(6):590-7.

7. Qasim Z, Brenner M, Menaker J, Scalea T. Resuscitative endovascular balloon occlusion of the aorta. Resuscitation. 2015;96:275-9.

8. Dubose JJ, Scalea TM, Brenner M, Skiada D, Inaba K, Cannon J, Moore L, Holcomb J, Turay D, Arbabi CN, Kirkpatrick A, Xiao J, Skarupa D, Poulin N; AAST AORTA Study Group. The AAST prospective Aortic Occlusion for Resuscitation in Trauma and Acute Care Surgery (AORTA) registry: data on contemporary utilization and outcomes of aortic occlusion and resuscitative balloon occlusion of the aorta (REBOA). J Trauma Acute Care Surg. 2016;81(3):409-19.

9. Morrison JJ, Ross JD, Rasmussen TE, Midwinter MJ, Jansen JO. Resuscitative endovascular balloon occlusion of the aorta: a gap analysis of severely injured UK combat casualties. Shock. 2014;41(5):38893.

10. Manzano Nunez R, Naranjo MP, Foianini E, Ferrada P, Rincon E, García-Perdomo HA, et al. A meta-analysis of resuscitative endovascular balloon occlusion of the aorta (REBOA) or open aortic cross-clamping by resuscitative thoracotomy in non-compressible torso hemorrhage patients. World J Emerg Surg. 2017;12(1):30.

11. Johnson MA, Davidson AJ, Russo RM, Ferencz SE, Gotlib O, Rasmussen TE, et al. Small changes, big effects: the hemodynamics of partial and complete aortic occlusion to inform next generation resuscitation techniques and technologies. J Trauma Acute Care Surg. 2017;82(6):1106-11.

12. Aso $S$, Matsui $H$, Fushimi $K$, Yasunaga $H$. Resuscitative endovascular balloon occlusion of the aorta or resuscitative thoracotomy with aortic clamping for noncompressible torso hemorrhage: a retrospective nationwide study. J Trauma Acute Care. 2017;82(5):910-4.

13. Weltz AS, Harris DG, O'Neill NA, O'Meara LB, Brenner ML, Diaz JJ. The use of resuscitative endovascular balloon occlusion of the aorta to control hemorrhagic shock during video-assisted retroperitoneal debridement or infected necrotizing pancreatitis. Int J Surg Case Rep. 2015;13:15-8.

14. Gamberini E, Coccolini F, Tamagnini B, Martino C, Albarello $V$, Benni $M$, et al. Resuscitative Endovascular Balloon Occlusion of the Aorta in trauma: a systematic review of the literature. World J Emerg Surg. 2017;12:42.

15. Okada A, Nakamoto O, Komori M, Arimoto H, Rinka $\mathrm{H}$, Nakamura $\mathrm{H}$. Resuscitative endovascular balloon occlusion of the aorta as an adjunct for hemorrhagic shock due to uterine rupture: a case report. Clin Case Rep. 2017;5(10):1565-8.

16. Daley J, Morrison JJ, Sather J, Hile L. The role of resuscitative endovascular balloon occlusion of the aorta (REBOA) as an adjunct to ACLS in non-traumatic cardiac arrest. Am J Emerg Med. 2017;35(5):731-6.

17. Doucet J, Coimbra R. REBOA: is it ready for prime time? J Vasc Bras. 2017;16(1):1-3.

18. Taylor RJ 3rd, Harvin JA, Martin C, Holcomb JB, Moore LJ. Vascular complications from resuscitative endovascular balloon occlusion of the aorta: life over limb? J Trauma Acute Care Surg. 2017;83(1 Suppl 1):S120-S3.

19. DuBoseJJ. Howldoit: partial resuscitativeendovascular balloon occlusion of the aorta (P-REBOA). J Trauma Acute Care Surg. 2017;83(1):197-9.

20. Joint Trauma System Clinical Practice Guideline. 
Resuscitative Endovascular Balloon Occlusion of the Aorta (REBOA) for Hemorrhagic Shock (CPG ID: 38). JTS CPG. 2017;1-21.

21. Lee J, Kim K, Jo YH, Lee JH, Kim J, Chung H, et al. Use of resuscitative endovascular balloon occlusion of the aorta in a patient with gastrointestinal bleeding. Clin Exp Emerg Med. 2016;3(1):55-8.

22. Ordoñez CA, Manzano-Nunez $R$, del Valle AM, Rodriguez F, Burbano P, Naranjo MP, et al. Uso actual del balón de resucitación aórtico endovascular (REBOA) en trauma. Rev Colomb Anestesiol. 2017;45(Suppl 2):30-8.

23. Tsurukiri J, Akamine I, Sato T, Sakurai M, Okumura E, Moriya M, et al. Resuscitative endovascular balloon occlusion of the aorta for uncontrolled haemorrahgic shock as an adjunct to haemostatic procedures in the acute care setting. Scand J Trauma Resusc Emerg Med. 2016;24:13. Erratum in: Scand J Trauma Resusc Emerg Med. 2016;24(1):72.

24. Okada Y, Narumiya H, Ishi W, liduka R. Anatomical landmarks for safely implementing resuscitative balloon occlusion of the aorta (REBOA) in zone 1 without fluoroscopy. Scand J Trauma Resusc Emerg Med. 2017;25(63):1-5.

25. Johnson MA, Neff LP, Williams TK, DuBose JJ; EVAC Study Group. Partial resuscitative balloon occlusion of the aorta (P-REBOA): Clinical technique and rationale. J Trauma Acute Care Surg. 2016;81(5 Suppl 2 Proceedings of the 2015 Military Health System Research Symposium):S133-7.

26. Russo RM, Neff LP, Lamb CM, Cannon JW, Galante JM, Clement NF, et al. Partial Resuscitative Endovascular Balloon Occlusion of the Aorta in Swine Model of Hemorrhagic Shock. J Am Coll Sur. 2016;223(2):359-68.

27. Madurska MJ, Jansen JO, Reva VA, Mirghani $\mathrm{M}$, Morrison JJ. The compatibility of computed tomography scanning and partial REBOA: a large animal pilot study. J Trauma Acute Care Surg. 2017;83(3):557-61.

28. Williams TK, Johnson A, Neff L, Hörer TM, Moore $L$, Brenner $M$, et al. "What's in a Name?" $A$ Consensus Proposal for a Common Nomenclature in the Endovascular Resuscitative Management and REBOA Literature. JEVTM. 2017;1(1):9-12.
29. DeSoucy E, Loja M, Davidson AJ, Faulconer ER, Simon MA, Russo RM, et al. Practice preferences using resuscitative endovascular balloon occlusion of the aorta for traumatic injury before and after the 2017 EndoVascular and Hybrid Trauma and Bleeding Management Symposium. JEVTM. 2017;1(1):13-21.

30. Codner PA, Brasel KJ. Emergency Department Thoracotomy: an update. Curr Trauma Rep. 2015;1(4):212-8.

31. Russo RM, Girda E, Kennedy V, Humphries MD. Two lives, one REBOA: hemorrhage control for urgent cesarean hysterectomy in a Jehovah's Witness with placenta percreta. J Trauma Acute Care Surg. 2017;83(3):551-3.

32. Karkos $C D$, Bruce IA, Lambert ME. Use of the intra-aortic balloon pump to stop gastrointestinal bleeding. Ann Emerg Med. 2001;38(3):328-31.

33. Nordon IM, Hinchliffe RJ, Loftus IM, Thompson MM. Pathophysiology and epidemiology of abdominal aortic aneurysms. Nat Rev Cardiol. 2011;8(2):92102.

34. Romagnoli A, Teeter W, Pasley J, Hu P, Hoehn M, Stein $D$, et al. Time to aortic occlusion: It's all about access. J Trauma Acute Care Surg. 2017;83(6):11614.

35. White JM, Cannon JW, Stannard A, Markov NP, Spencer JR, Rasmussen TE. Endovascular balloon occlusion of the aorta is superior to resuscitative thoracotomy with aortic clamping in a porcine model of hemorrhagic shock. Surgery. 2011;150(3):400-9.

36. Belenkiy SM, Batchinsky Al, Rasmussen TE, Cancio LC. Resuscitative endovascular balloon occlusion of the aorta for hemorrhage control: Past, present, and future. J Trauma Acute Care Surg. 2015;79(4 Suppl 2):S236-42.

37. Saito $N$, Matsumoto $H$, Yagi T, Hara $Y$, Hayashida $\mathrm{K}$, Motomura $\mathrm{T}$, et al. Evaluation of the safety and feasibility of resuscitative endovascular balloon occlusion of the aorta. J Trauma Acute Care Surg. 2015;78(5):897-903.

38. SridharS, GumbertSD, Stephens C, Moore LJ, Pivalizza EG. Resuscitative Endovascular Balloon Occlusion of the Aorta: principles, initial clinical experience, and considerations for the anesthesiologist. Anesth Analg. 2017;125(3):884-90. 
39. Costantini TW, Coimbra R, Holcomb JB, Podbielski JM, Catalano R, Blackburn A, Scalea TM, Stein DM, Williams L, Conflitti J, Keeney S, Suleiman G, Zhou $T$, Sperry J, Skiada D, Inaba K, Williams BH, Minei $J P$, Privette A, Mackersie RC, Robinson BR, Moore FO; AAST Pelvic Fracture Study Group. Current management of hemorrhage from severe pelvic fractures: results of an American Association for the Surgery of Trauma multi-institutional trial. J Trauma Acute Care Surg. 2016;80(5):717-23.

40. Keller BA, Salcedo ES, Williams TK, Neff LP, Carden AJ, Li Y, et al. Design of a cost-effective, hemodynamically adjustable model for resuscitative endovascular balloon occlusion of the aorta (REBOA) simulation. J Trauma Acute Care Surg. 2016;81(3):606-11.

41. Teeter WA, Matsumoto J, Idoguchi K, Kon Y, Orita $T$, Funabiki $T$, et al. Smaller introducer sheaths for REBOA may be associated with fewer complications. J Trauma Acute Care Surg. 2016;81(6):1039-45.

42. Linnebur $M$, Inaba $K$, Haltmeier $T$, Rasmussen
$T E$, Smith J, Mendelsberg R, et al. Emergent nonimage-guided resuscitative endovascular balloon occlusion of the aorta (REBOA) catheter placement: a cadaver-based study. J Trauma Acute Care Surg. 2016;81(3):453-7.

43. Reynolds $C L$, Celio AC, Bridges LC, Mosquera C, O'Connell B, Bard MR, et al. REBOA for the IVC? Resuscitative balloon occlusion of the inferior vena cava (REBOVC) to abate massive hemorrhage in retro-hepatic vena cava injuries. J Trauma Acute Care Surg. 2017;83(6):1041-6.

Received in: 04/01/2018

Accepted for publication: 16/01/2018

Conflict of interest: none.

Source of funding: none.

\section{Mailing address:}

Marcelo Augusto Fontenelle Ribeiro Júnior E-mail:mfribeiro@prof.unisa.br / drmribeiro@gmail.com (cc) BY 